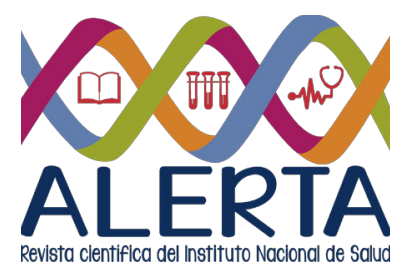

\title{
Validación de hisopo de Moore en cadena frío para la recuperación de Vibrio cholerae
}

Abel Antonio Godoy ${ }^{1}$, Tatiana García de Avilés $^{1}$ y Dikson Rolando Batres ${ }^{1}$

${ }^{1}$ Laboratorio Nacional de Referencia del Instituto Nacional de Salud
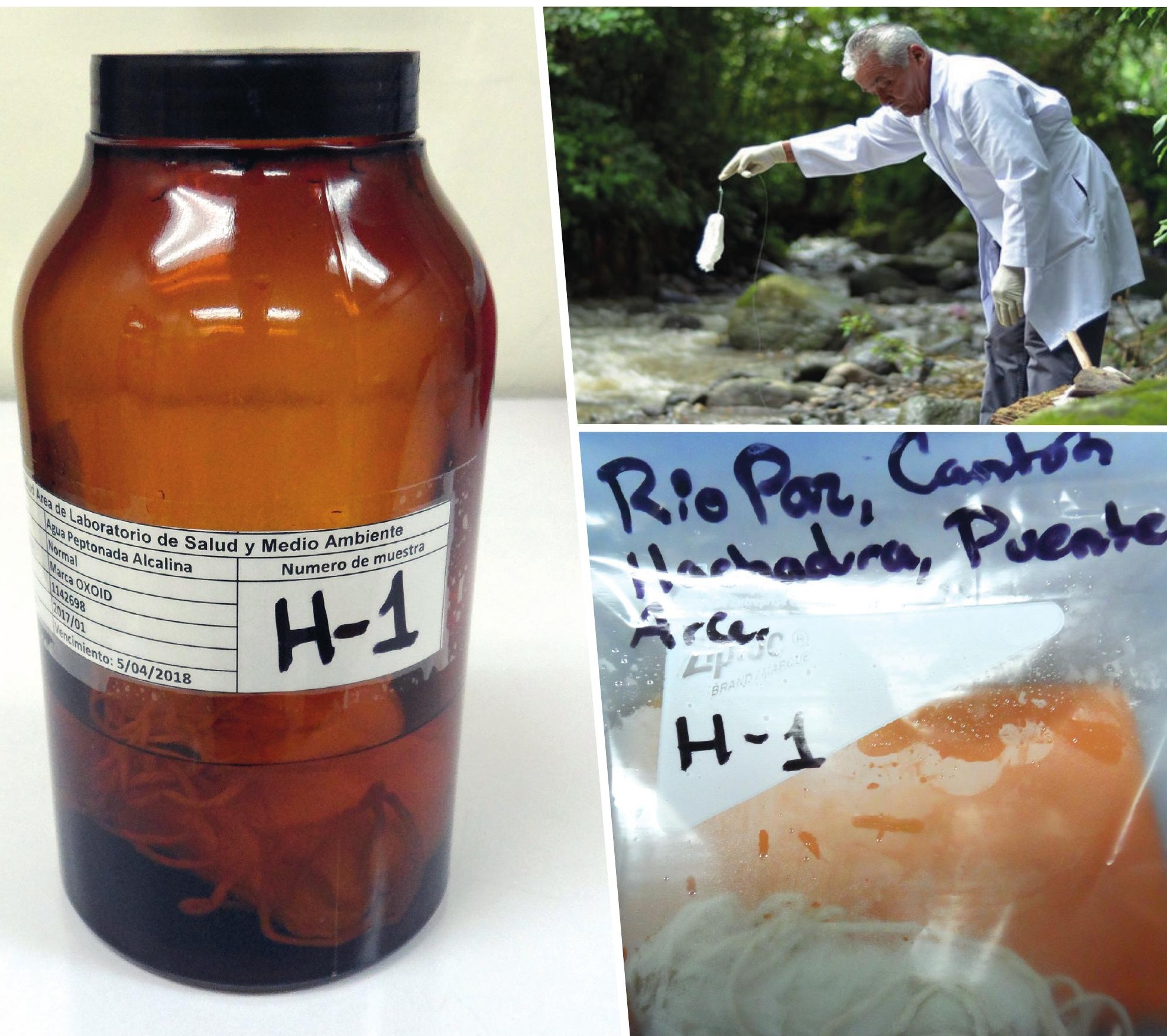
El cólera es una infección intestinal aguda causada por la ingestión de alimentos o agua contaminados con heces o vómitos de personas enfermas o portadoras de la bacteria Vibrio cholerae. Es una enfermedad muy virulenta que afecta tanto a niños como adultos y puede ser mortal en cuestión de horas ${ }^{1}$. Existen dos biotipos de Vibrio cholerae: O1, el biotipo clásico y el biotipo El Tor. Estos se dividen antigénicamente en los serotipos Ogawa e Inaba y rara vez el Hikojima. Pero durante el brote de cólera ocurrido en el Este de la India y en Bangladesh, entre 1992 y 1993, apareció un nuevo serogrupo de Vibrio cholerae no-O1, capaz de producir exotoxina y por tanto cólera clínico, pero que no contiene el antígeno $\mathrm{O} 1$, el denominado a partir de entonces Vibrio cholerae O:139, también causante de enfermedad ${ }^{2}$.

La vigilancia de Vibrio cholerae en agua superficial se realiza mediante la técnica de Hisopo de Moore (HM) (Figuras 1 y 2), que constituye la técnica práctica y eficaz para su detección. De acuerdo con CDC/NCID OPS 1994 "Métodos de Laboratorio para el Diagnóstico de Vibrio cholerae", el HM debe transportarse en frascos de vidrio con Agua Peptonada Alcalina (APA) hasta su entrega en el laboratorio, permitiendo durante su transporte que las baterías patógenas, incluyendo Vibrio cholerae, se multipliquen exponencialmente. Esto se convierte en un riesgo biológico para el transportista de la muestra. Para la reducción del riesgo se propone el transporte de HM en cadena de frío $\left(4-8^{\circ} \mathrm{C}\right)$ para detener la multiplicación bacteriana protegido en hieleras resistente a golpes (Figuras 3 y 4 ).

Para la validación se estudiaron 79 HM de ríos y lagos de El Salvador. Cada muestra se tomó por duplicado para ser transportadas una muestra en cadena de frío y otra en caldo APA a temperatura ambiente. Los HM trasladados en ambos métodos (APA /cadena de frío) fueron recibidos e inoculados en los frascos de vidrio con $350 \mathrm{~mL}$ de APA al $10 \% \mathrm{NaCl}$ durante 16 - 18 horas, a $35^{\circ} \mathrm{C} \pm 2$, para luego inocular en tubos con $10 \mathrm{~mL}$ APA al $10 \% \mathrm{NaCl}$ durante $6-8$ horas a $35^{\circ} \mathrm{C} \pm 2$. Se realizó la recuperación e identificación en Agar TCBS según lo establecido por "Métodos de Laboratorio para el

\section{Diagnóstico de Vibrio cholerae" ${ }^{1,4}$.}

Los resultados obtenidos del transporte del HM en cadena de frío con sus intervalos de confianza fueron: Sensibilidad de 94.64\% (87.85 - 100.0), especificidad de $69.57 \%$ (48.59 - 90.54), valor predictivo positivo de $88.33 \%$ (79.38 - 97.29), valor predictivo negativo de $84.21 \%(65.18$ - 100.0) y un índice de Youden de 0.64 $(0.45-0.84)^{5}$. Además, se evaluó un índice Kappa de 0.67 con un nivel de concordancia considerable ${ }^{6}$ entre resultados. Se concluye que el método de transporte del $\mathrm{HM}$ en cadena de frío es factible en nuestro medio por sus resultados confiables en la recuperación de Vibrio cholerae en agua superficial y la disminución del riesgo que representan al método tradicional.

\section{Referencias bibliográficas}

1. Acuña MT. Importancia de la vigilancia de la calidad microbiológica de alimentos en la prevención y control del cólera. En: Taller "El papel de laboratorio en la prevención y control del cólera": 8 de noviembre de 2013, San José, Costa Rica. Instituto Costarricense de Investigación y Enseñanza en Nutrición y Salud (INCIENSIA).

2. Caffer MI, et al. Manual de Procedimientos, aislamiento, identificación y caracterización de Vibrio cholerae. Departamento de Bacteriología, Instituto Nacional de Enfermedades Infecciosas A.N.L.I.S. "Dr. Carlos G. Malbrán". Centro Regional de Referencia del para América del Sur. Buenos Aires: WHO Global Salm Surv; 2007. p. 1-46.

3. Gini GA. Manual de procedimientos para la identificación de las bacterias con importancia clínica. Guatemala: USAC; 1995. p.77-81.

4. Satcher D, Hughes J, Carlyle G. Métodos de laboratorio para el diagnóstico de Vibrio cholerae. Washington D.C.: CDC/NCID/OPS; 1994. p. 1-147.

5. Noguera TL, Cadarso CM (dir). Metodología ROC en la evaluación de medidas antropométricas como marcadores de la hipertensión arterial. Aplicación a población gallega adulta [Proyecto de Fin de Máster]. [Santiago de Compostela, Galicia, España]: Universidad de Santiago Compostela, Facultad de Matemáticas; 2010.

6. Cerda J, Villarroel L. Evaluación de la concordancia inter-observador en investigación pediátrica: Coeficiente de Kappa. Rev Chil Pediatr 2008; 79 (1): p. 54-58.

\section{Forma recomendada de citar}

Godoy AA, García de Avilés T, Batres DR. Validación de hisopo de Moore en cadena frío para la recuperación de Vibrio cholerae. Revista ALERTA. 2018; 1 (1): 61-3. 


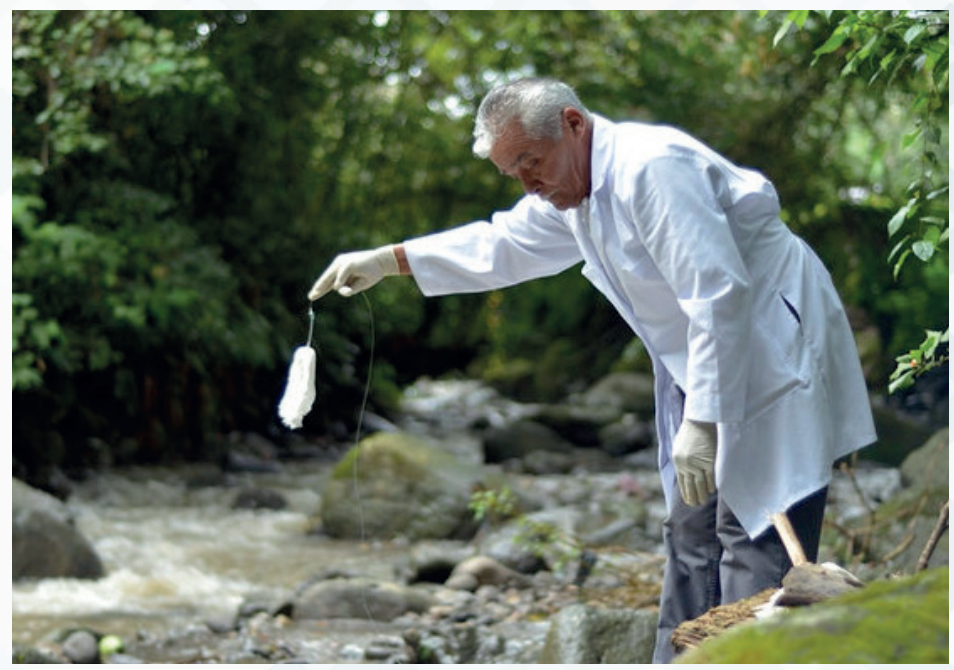

Figura 1.

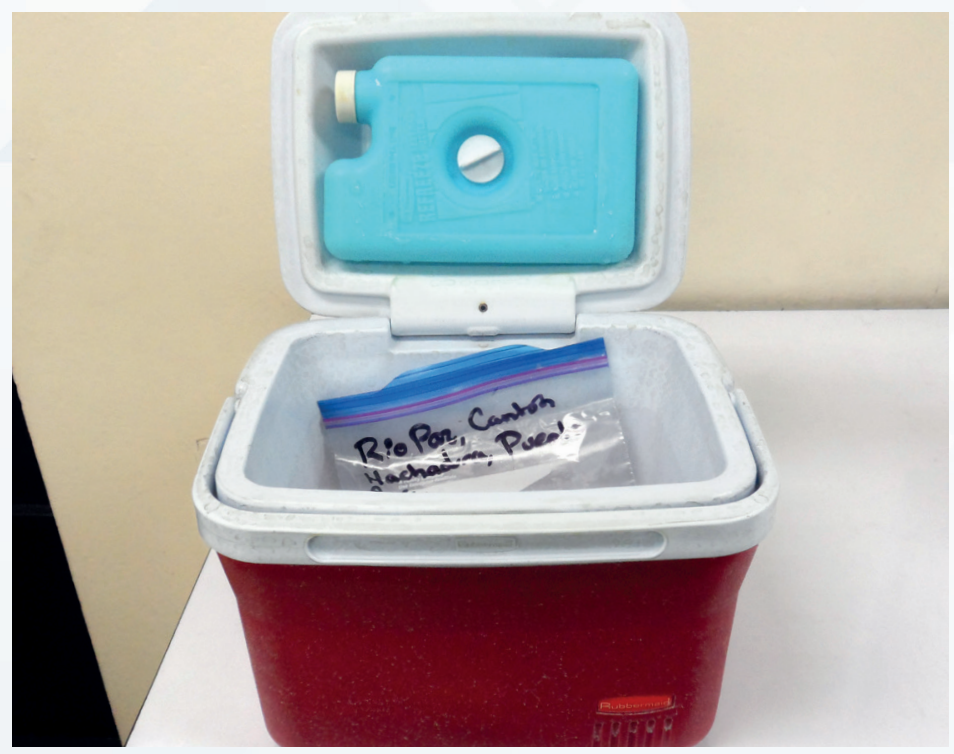

Figura 3.

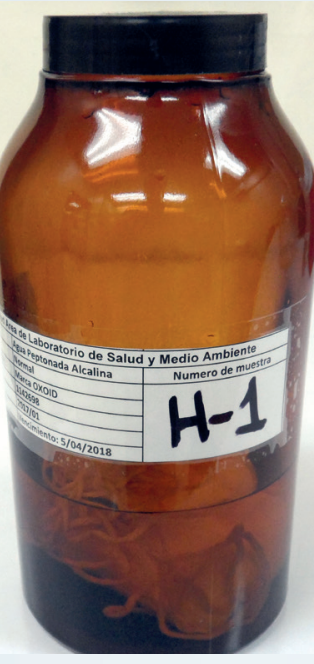

Figura 2.

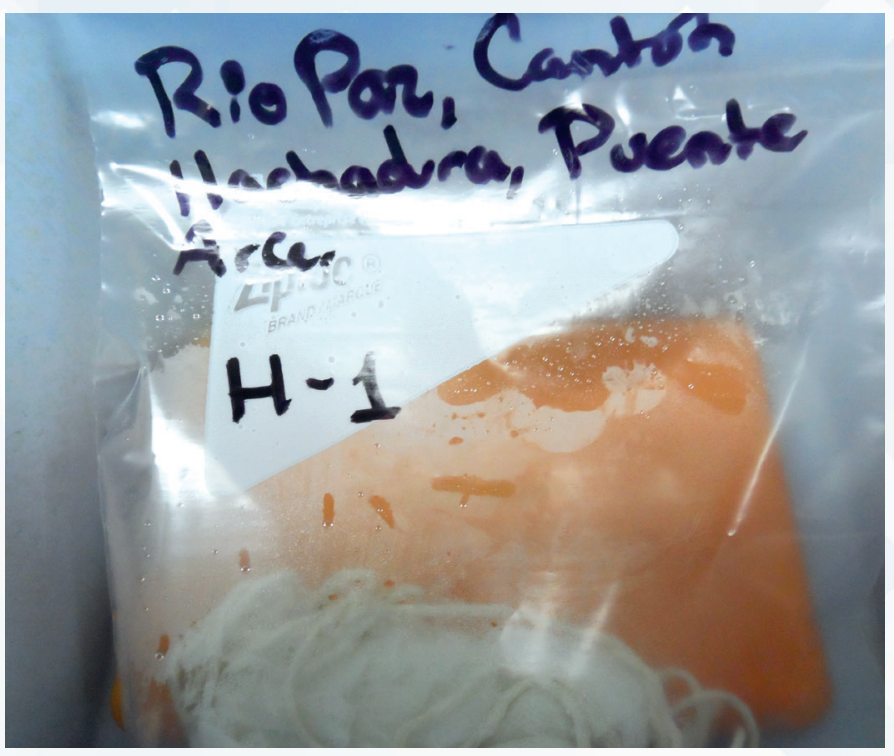

Figura 4. 